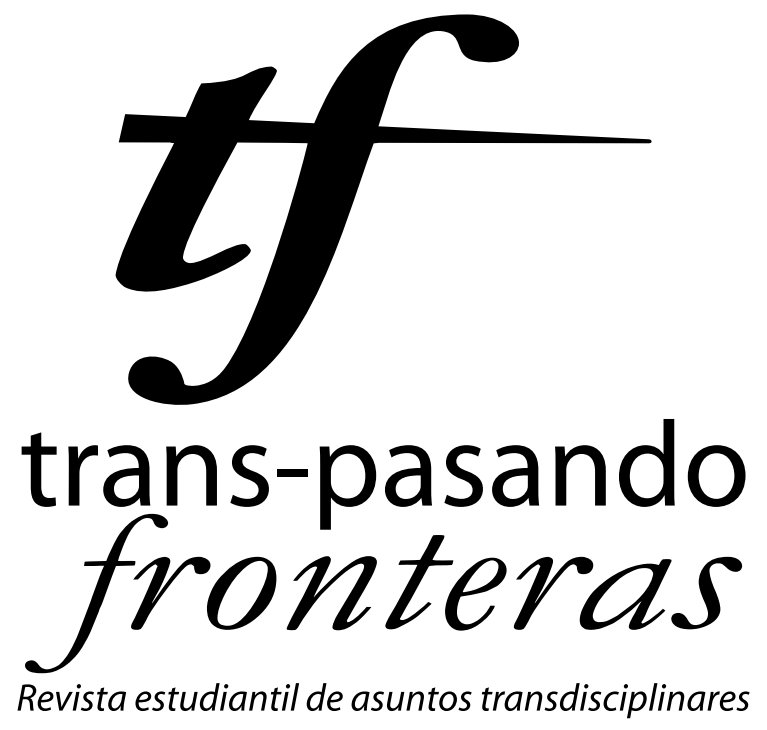

Una publicación de

Facultad de Derecho y Ciencias Sociales

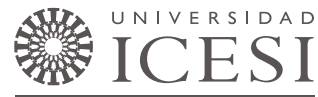




\title{
Consulta previa en casos de minería para comunidades indígenas y tribales"
}

\author{
Claudia Jimena Abello** \\ (claudiaj.abello@gmail.com)
}

Artículo de investigación científica y tecnológica recibido el 28/06/2012 y aprobado el 17/10/2012.

Como citar este artículo:

ABELLO C. Claudia Jimena (2012). "Consulta previa en casos de mineria para comunidades indígenas y tribales”. En: Trans-pasando Fronteras, Núm. 2, pp. 111-124. Cali, Colombia: Centro de Estudios Interdisciplinarios, Jurídicos, Sociales y Humanistas (CIES), Universidad Icesi.

\begin{abstract}
Resumen
Este artículo hace un recorrido sobre la jurisprudencia de la Corte Constitucional sobre consulta previa y la minería. El objetivo es establecer las principales reglas, que ha creado la Corte al ponderar el derecho a la consulta previa versus el derecho del Estado a la explotacion de recursos naturales. También, se intentará dar un esbozo de lo que entiende la Corte Constitucional como consulta previa y el procedimiento a seguir. Finalmente se hace una pequeña reflexión sobre el multiculturalismo y los derechos diferenciales.
\end{abstract}

Palabras claves:

Consulta previa, jurisprudencia Corte Constitucional colombiana, minería, multiculturalismo.

* Gracias a mi compañera Paola Villegas de Derecho Constitucional II. Sin ella este trabajo no hubiera sido posible.

** Estudiante en séptimo semestre de Antropología y cuarto semestre de Derecho de la Universidad Icesi. Sus áreas de interés la antropología jurídica, los derechos humanos y el derecho ambiental. Es asistente de investigación del programa de Antropología en la universidad Icesi. Miembro e investigadora del semillero de derechos humanos GANDHI de la Universidad Icesi. 


\section{Introducción}

El siguiente ensayo nace en el curso de Derecho Constitucional II, en el que se planteó como actividad semestral la realización de una línea jurisprudencial. Su fin es analizar el papel que desempeña la Corte Constitucional como máximo intérprete de la Constitución, y comprender su actividad judicial.

Para la realización de la línea jurisprudencial, se eligió el tema del derecho a la consulta previa que tienen las comunidades indígenas y tribales. Específicamente cuando se llevan a cabo proyectos que afectan directamente a la comunidad o a su territorio. Al iniciar la investigación, se llegó a la conclusión de que el derecho a la consulta previa ha sido asumido por la Corte Constitucional Colombiana de una forma muy amplia, ya que ha abordado diversas problemáticas como la educación, la construcción de carreteras, los puertos marítimos, las explotaciones petroleras y mineras, entre otros. En consecuencia, el análisis se delimitó al tema de la consulta previa por el desarrollo de proyectos mineros y/o petroleros, y se decidió plantear como problema jurídico ${ }^{1}$ lo siguiente: ¿Se vulnera el derecho fundamental de las comunidades étnicas a la consulta previa cuando se realizan obras, proyectos y/o actividades mineras o petroleras, que tengan la potencialidad de afectar sus territorios, con fundamento en la potestad que tiene el Estado colombiano para explotar los recursos naturales en el subsuelo del territorio nacional?

En las siguientes páginas se presentarán los resultados obtenidos del análisis de dicho problema jurídico. Se iniciará con una breve descripción del vuelco multicultural que se ha dado en América Latina durante las últimas décadas, con el fin de entender las razones por las cuales en Colombia, con la constitución de 1991, se le dio por primera vez un reconocimiento real a los derechos de las comunidades indígenas y tribales. Luego, se mostrará el trabajo doctrinal que la Corte Constitucional ha desarrollado en sus fallos para hacer efectivo el ejercicio de los derechos de estas comunidades, tomando como centro aquellas sentencias que corresponden al tema de la línea. Finalmente, se presentará las conclusiones y una crítica al trabajo que la Corte Constitucional ha desarrollado sobre este tema.

$1 \quad$ El problema jurídico puede equivaler a la pregunta central o al problema de investigación en una investigación en otras Ciencias Sociales. 


\section{El giro multicultural: unidos en la diversidad}

Durante las últimas tres décadas en América Latina, se ha venido desarrollando un fenómeno que algunos han denominado como el "vuelco multicultural". Se ha llamado así porque durante ese tiempo, 15 países Latinoamericanos han llevado a cabo procesos de redefinición de la nación. Diríamos pues, que muchas naciones pasaron de un concepto homogenizado de nación, a una visión más amplia y multicultural de la misma. Al respecto, podemos destacar lo que Catalina Botero (2003) propone como un Estado multicultural:

\footnotetext{
“aquel en el cual conviven simultáneamente los miembros de la sociedad mayoritaria con grupos que son calificados como minorías nacionales y/o grupos étnicos. En consecuencia, las normas que reconocen y protegen la diferencia cultural se dirigen, fundamentalmente, a aquellos grupos que pueden ser catalogados dentro de una de estas dos categorías" (Botero, 2003:46-87).
}

En Colombia, por ejemplo, la constitución de 1886 construyó una nación homogénea compuesta por una sola raza mestiza, un solo Dios católico y una sola lengua: castellano. De acuerdo con estas premisas, en Colombia se llevaron a cabo numerosas políticas públicas para que los "salvajes vayan reduciéndose a la vida civilizada", tal como lo dicta la ley 89 de 1890. Pero fue gracias a las numerosas luchas agrarias y políticas de grupos de indígenas, afros y solidarios, sumado a esfuerzos internacionales, que se logró transformar la realidad jurídica de las minorías étnicas (Caviedes, 2002).

Trasportémonos entonces a 1991, un momento de alta agitación política del país, donde se conformó la Asamblea Nacional Constituyente. Allí tendríamos, tres representantes indígenas: Francisco Rojas Birry, miembro de una comunidad Embera, elegido por la Organización Indígena de Colombia; Lorenzo Muelas, miembro de la comunidad Guambiana, elegido por el Movimiento de Autoridades Indígenas de Colombia; y Alfonso Peña, miembro del grupo indígena guerrillero desmovilizado Quintín Lame (Bonilla, 2006:124-126).

Para Daniel Bonilla (2006), la constitución del 91 le brindó a las comunidades la oportunidad de construir unos principios constitucionales, que permitieran enmendar la violencia y exclusión física y jurídica, de las comunidades. En palabras de Bonilla una "justicia correctiva" (Bonilla, 2006:131). El argumento central de los líderes indígenas, mostraba que es poco probable que el Estado colombiano aplique hoy en día políticas de homogenización, 
como en otras épocas. Aún así, lo hecho en el pasado repercute enormemente, aumentado las desigualdades generadas entre indígenas y no indígenas. Por lo tanto, es necesario que el Estado se ponga en la tarea de incluir y a la vez reconocer la diversidad étnica.

Pero no todo fue color de rosa, Bonilla (2006) señala en el texto La Constitución Multicultural, dos fuertes tensiones plasmadas en la Constitución. La primera de ellas, entre la igualdad y la diferencia; representada, por un lado, en el deseo de las comunidades étnicas de ser incluidas, sin discriminación, en el proceso de construcción de la nación; por otro lado, el reconocimiento a la diversidad étnica, que implica la protección y promoción de las culturas minoritarias. La segunda tensión, se encuentra entre unidad y autonomía; unidad al defender la promoción de los derechos humanos y autonomía de conservar una jurisdicción propia.

\footnotetext{
"Estos dos conflictos de valores muestra claramente que la carta política se mueve como un péndulo entre los valores políticos de la unidad cultural y la diferencia cultural. (...) El movimiento de péndulo entre la diversidad y unidad cultural puede verse también en la promulgación de derechos de autogobierno y de facultades jurisdiccionales para los grupos indígenas y los limites que fueron impuestos" (Bonilla, 2006:141-142).
}

En pocas palabras, las reformas constitucionales que se dieron a finales de los ochenta y principios de los noventa, son el punto de llegada de numerosas luchas nacionales e internacionales de diferentes grupos étnicos. Estas reformas, permitieron reconocer la diversidad étnica y cultural de los países, concediendo así, numerosos derechos políticos y sociales a minorías que antes estaban destinadas a ser integradas a la sociedad mayor. Pero esta transformación no es renuente de tensiones, en el texto constitucional se plasmaron valores y principios que se contraponen los unos con los otros. Por eso, es necesaria la actuación de la Corte Constitucional como máximo intérprete de la constitución.

\section{Trabajo de la Corte Constitucional en el caso concreto}

En esta sección, se expondrán en orden cronológico las sentencias en las que la Corte Constitucional ha solucionado casos que corresponden a nuestro problema jurídico. También, se señalarán las sentencias conceptualizadoras en las que el trabajo de la Corte 
Constitucional ha sido establecer argumentos que soportan la consulta previa. Este trabajo estará dividido en cinco sub-partes. Se comenzará con la sentencia fundadora² ${ }^{2}$ es decir la de mayor antigüedad, de la que parten todas las de sentencias análogas. Para luego continuar con la SU-039/1997, caso representativo del conflicto indígena y la explotación petrolera. Pasaremos después, por la T-880/2006, donde se enfrenta la etnia Motilón Bari a ECOPETROL por la explotación de un poso minero en Tibú (Norte de Santander). Continuaremos, con la T-769/2009 donde se enfrenta la comunidad Embera y la Muriel Mining Corporation. Siguiendo, con la T-1045A/2010 en la que se enfrenta la comunidad negra de La Toma con el empresario Héctor Jesús Sarria. Finalizaremos con la sentencia T-129/2011, en la cual los resguardos Emberá-Katío, Chidima-Tolo y Pescadito presentan una querella contra la Gold Plata Corporation.

Antes de inciar con la cronología, es pertinente explicar que el concepto de consulta previa no es monolítico, es decir, no se presenta de la misma manera en todas las sentencias. Sabemos que existen tratados internacionales como: el 169 de OIT, la Ley 21 de 1991 y el decreto 1320 de 1998, que intentan regular esta materia. Pero estos tratados, leyes y decretos no establecen un concepto univoco de la consulta previa. Por eso, es necesario que se analice caso por caso la jurisprudencia de la Corte Constitucional, para saber las reglas que se aplican a casos análogos.

En la sentencia fundadora, no se discute sobre el derecho fundamental a la consulta previa, cuando se intentan realizar proyectos mineros. En ella, la Corte Constitucional se pronuncia por primera vez, acerca de la procedencia de la acción de tutela para la defensa de los derechos de las comunidades indígenas, en casos que involucran la explotación de los recursos naturales del Estado. En síntesis, el conflicto se presenta cuando la Corporación Nacional de Desarrollo del Chocó (CODECHOCO) y la Compañía de Maderas del Darién (MADARIEN) vulneran y amenazan los derechos fundamentales de la comunidad indígena Emberá-Katío de Chajeradó. Entre ellos, el derecho a la vida, al trabajo, a la propiedad, a la integridad étnica y el derecho a la especial protección del Estado como grupo étnico, entre otros.

2 En relación a estos fallos, se puede decir que son "usualmente proferidos en el periodo inicial de la actividad de la corte (1991-1993), en los que se aprovecha sus primeras sentencias de tutela o de constitucionalidad para hacer enérgicas y muy amplias interpretaciones de derechos (u otros institutos) constitucionales" (López, 2006:164). 
Los hechos inician cuando MADARIEN, en asociación con el señor Reinerio Palacios, realizaron una explotación forestal en Chajeradó, Municipio de Murindo (Antioquia). Razón por la cual, la comunidad indígena Emberá-Katío presentó la tutela. En su defensa, los representantes legales de los demandados alegaron, que la tutela en este caso no procede, porque la pretensión de la comunidad es resarcitoria. Por lo tanto, debieron haber acudido a la acción colectiva, como medio idóneo para obtener la indemnización. Para MADARIEN la acción de tutela es contraria al artículo 86 de la Carta, ya que es de naturaleza preventiva.

$\mathrm{Al}$ analizar el caso concreto y los argumentos de las partes, la Corte Constitucional declara procedente la tutela. Porque es importante entender que las comunidades indígenas son un sujeto colectivo diferente a cualquier grupo de personas, que se unen con el objetivo de defender sus derechos cumunales. En la sentencia se expone:

\footnotetext{
"Los derechos fundamentales de las comunidades indígenas no deben confundirse con los derechos colectivos de otros grupos humanos. La comunidad indígena es un sujeto colectivo y no una simple sumatoria de sujetos individuales que comparten los mismos derechos o intereses difusos o colectivos (CP art. 88). En el primer evento es indiscutible la titularidad de los derechos fundamentales, mientras que en el segundo los afectados pueden proceder a la defensa de sus derechos o intereses colectivos mediante el ejercicio de las acciones populares correspondientes" (Sentencia T-380/1993).
}

Este argumento es importante para el análisis de la línea por dos razones. En primer lugar, establece que los derechos de las comunidades indígenas pueden ser protegidos mediante tutela. Debido a su condición especial de "sujeto colectivo", no son la suma de individuos que comparten una causa común. En segundo lugar, establece la tutela como un mecanismo idóneo frente a la vulneración de derechos, que produce la explotación de recursos naturales en territorios indígenas.

A continuación, se presentarán las sentencias análogas sobre minería y consulta previa que resolverán nuestro problema jurídico. Como el tema es tan específico, sólo encontramos seis sentencias que se ajustan a los criterios que inicialmente se plantearon. Los hechos que a grandes rasgos conectan estas sentencias son: la concesión de la exploración y/o explotación minera o petrolera, por parte del Estado a una empresa o par- 
ticular, en territorio de comunidades negras o indígenas. La vulneración del derecho de consulta previa se da, entonces, cuando no se hace la consulta, o cuando los mecanismos por la que se realizaron no fueron idóneos.

Uno de los primeros casos, tal vez el más emblemático, es el caso de la SU-039 de 1997. En el año de 1992, a la empresa Colombia Inc. se le concedió un permiso para la explotación de hidrocarburos en territorio de la comunidad indígena U'wa. En febrero de 1995, la empresa realiza una reunión informativa en Arauca, donde comunica a la comunidad los alcances del proyecto. El defensor del pueblo, en nombre de los indígenas, interpone una tutela, argumentando que la reunión no fue una consulta previa y que debido a esto, se les violan derechos fundamentales. En esta sentencia, la Corte Constitucional establece que es una tarea del Estado proteger la integridad étnica, social, económica y cultural de las comunidades, ante la explotación de recursos naturales en sus territorios. También instaura la consulta previa y la tutela como un medio idóneo y necesario para preservar los derechos indígenas, consagrados en la constitución y en los artículos 6, 7 y 15 del convenio 169 de la OIT.

La siguiente sentencia en la línea, es la T -880/2006. En ella, la comunidad Motilón Barí, tutela ante la vulneración a su derecho de consulta previa, por la perforación del pozo Álamo en el Municipio de Tibú ( Norte de Santander), por parte de la Empresa Colombiana de Petróleos ECOPETROL S.A. La empresa desconoce el territorio indígena, practicando una reunión informativa que no cumple con los estándares de consulta previa. La Corte Constitucional, nombra distintas normas que protegen lo derechos colectivos a la consulta previa y la diversidad étnica de las comunidades indígenas y tribales, tales como: los artículos 1,7, 63,70, 171, 176, 246, 329 y 330 de la Constitución Política; los articulo 6, 7 y 15 del convenio 169 de la OIT (parte del bloque de constitucionalidad), la ley 121 de 1991 que ratifica el convenio y el decreto 1397 de 1998 que regula la consulta previa en Colombia. Concluye que la consulta previa debe ser guiada por el mutuo respeto y la buena fe, por el conocimiento pleno sobre los proyectos y la afectación que estos producen para la integridad de las comunidades.

En esta sentencia, la Corte Constitucional establece que la simple notificación de la explotación no es consulta previa, es necesaria una concertación. Cuando no se llegue a un acuerdo entre las partes, la decisión debe ser tomada por la autoridad pertinente desprovista de arbitrariedad y autoritarismo: 
"En todo caso deben arbitrarse los mecanismos necesarios para mitigar, corregir o restaurar los efectos que las medidas de la autoridad produzcan o puedan generar en detrimento de la comunidad o de sus miembros."'(T-039/1997)

El siguiente caso, corresponde a la sentencia T-769/2009, en el que está en conflicto la empresa minera Muriel Mining Corporation con la comunidad indígena Emberá y las comunidades negras de los departamentos de Antioquia y Chocó. A la empresa minera, se le concede una licencia para explotar el subsuelo en territorios donde habitan estas comunidades étnicas, ya que se había realizado "debidamente" la consulta previa. Pero se instaura la tutela, porque las comunidades étnicas consideran que el proceso de consulta previa no se hizo de la forma adecuada. Frente a esta situación, la Corte Constitucional en su fallo reiteró los tres aspectos de alcance de la consulta y su contenido esencial. En ellos, se constata que el principio de la buena fe debe esta inmerso durante el proceso, es decir que la consulta debe hacerse de forma honesta y completa. De no ser así, las comunidades étnicas tienen el derecho a defenderse, mediante los mecanismos que resultes más rápidos y eficaces para evitar los posibles daños, que pueda causar la omisión de la consulta.

1. "La consulta resulta obligatoria cuando las medidas que se adopten sean susceptibles de afectar específicamente a las comunidades aborígenes, en su calidad de tales".

2. Aunque el procedimiento de consulta previa no tenga reglas de manera estricta en el convenio 169 de la OIT, el trámite debe estar ceñido al principio de la buena fé, es decir: el mutuo respeto, la transparencia y la confianza recíproca entre las partes. La consulta está basada en la comunicación y el entendimiento por esta razón se debe procurar que:

- "Que la comunidad tenga conocimiento pleno sobre los proyectos"

- "Que igualmente sea enterada e ilustrada a cabalidad sobre la manera como la ejecución de los proyectos puede conllevar una afectación o variación sobre sus derechos, sus tradiciones y, en general, el hábitat".

- "La comunicación abierta, oportuna, libre y sin interferencias extrañas, procurándose la convocatoria de los representantes legítimos".

3. La consecuencia jurídica de la omisión frente al deber de la consulta previa, habrá un amparo constitucional por medio de la cual las comunidades pueden hacer efectivas las medidas necesarias" (Sentencia T-769/2009). 
En la sentencia mencionada, también se exponen los tres objetivos de la consulta previa, retomado la sentencia T-039/1997. Adicionalmente, se afirma que: "se entiende también, como aparejada a la consulta, la información o notificación que se le hace a la comunidad indigena sobre un proyecto de exploración o explotación de recursos naturales" (T-769/2009). Lo que indica, un pequeño cambio en la jurisprudencia de la Corte. De la misma manera se establece que el Ministero de Ambiente es el encargado de verificar: "i) si existe una vulneración de los derechos de los indígenas y afrodescendientes en su territorio; $y$ ii) determinar el impacto ambiental que se genera en dichas zonas" (T-769/2009). Finalmente, la Corte utiliza el caso Saramaka de la Corte Interamericana y la relatoría especial de la ONU (Anaya, 2010), para establecer el conocimiento libre e informado de las partes, convirtiendo las desiciones de las comunidades en vinculantes.

$\mathrm{Al}$ año siguiente, se presentó el caso en el que la comunidad tribal del corregimiento de la Toma, municipio de Suárez, Cauca, interpuso acción de tutela contra INGEOMINAS y la Alcaldía de Suárez, por haberle concedido una licencia de 10 años al señor Héctor Sarria para la explotación de un yacimiento de oro, cuyo desarrollo afectaría el territorio de carácter ancestral de la comunidad de la Toma. Hasta el momento no se había realizado la consulta previa a la comunidad. En su fallo, la Corte Constitucional reitera lo dicho en el caso anterior, acerca de los alcances de la consulta previa y las características de transparencia y respeto con las que se debe realizar, anexa las situaciones en las que se debe hacer la consulta previa a las comunidades indígenas o tribales, así:

1. "Cuando se adopten medidas legislativas o administrativas que afecten a las comunidades étnicas.

2. Antes de la explotación o exploración minera o de otros recursos naturales, que se encuentre en los territorios de comunidades indígenas o tribales.

3. Cuando sea necesario trasladar las comunidades nativas de sus tierras a otros sitios.

4. Antes de diseñar y ejecutar planes de formación profesional dirigidas a dicha población" (Sentencia T-1045A/2010).

En la sentecia T-045A/2010, se retoma los argumentos expresados en las sentencias T-769/2009 y SU-039/1997. Por lo tanto, se establece la consulta previa como un me- 
canismo donde prima la buena fe y la transparencia, al igual que la decisión objetiva y razonable de la autoridad estatal. También, se reitera el principio de conocimiento libre e informado establecido por las relatorias de la ONU y el caso Saramaka de la Corte Interamericana. Adicionalmente, menciona artículos de la Ley 685 de 2001 que exige:

1. “antes de empezar la exploración y explotación de un proyecto minero que se encuentre en territorio de las comunidades étnicas minoritarias, se debe desarrollar la consulta previa respectiva con las comunidades que puede ser o llegar a ser afectadas por dicho proyecto;

2. deberá estar aprobado el estudio y expedida la licencia ambiental respectiva, para poder iniciar los trabajos y obras mineras;

3. la autoridad minera deberá tener en cuenta y decidir sobre el derecho de prelación que les atañe a esas comunidades étnicas, de acuerdo con la ley” (T-045A/2010).

La última sentencia de esta línea jurisprudencia es la T-129/2011. Es una sentencia de gran extensión y complejidad porque presenta varios problemas jurídicos. En ella, se plantea que existe una vulneración a los derechos colectivos de las comunidades indígenas Emberá-Katío, Chidima-Tolo y Pescadito por la construcción de una carretera, una hidroeléctrica y la concesión de explotación de oro a la Gold Plata Corporation. En esta sentencia, la Corte hace un recuento de su jurisprudencia señalando los siguientes puntos: Primero, la importancia del consentimiento libre e informado al momento de realizar planes de desarrollo o inversión que tengan un alto impacto en las comunidades. Segundo, la consulta previa no es un poder de veto por parte de las comunidades sino:

\footnotetext{
"un espacio de disertación entre iguales en medio de las diferencias, oportunidad para que los organismos estatales y concesionarios del Estado puedan explicar de forma concreta y transparente cuáles son los propósitos de la obra y la comunidad pueda exponer cuáles son sus necesidades y puntos de vista frente a la misma" (Sentencia T-129/2011).
}

Tercero, establece que se deben fijar tiempos de revisión a corto, mediano y largo plazo cuando se implementen planes de desarrollo. Por lo tanto, no se plantea un tiempo 
único de realización de la consulta previa, ya que esto homogenizaría los procesos y desconocería las circunstancias materiales de las comunidades étnicas. Finalmente, la Corte Constitucional establece once reglas que se deben cumplir en caso de intervenir en territorios de comunidades étnicas, las cuales se encuentran anexas a este documento.

\section{Conclusiones}

Las conclusiones tienen dos partes. En la primera se explican los avances doctrinales que ha logrado la Corte Constitucional en materia de consulta previa y minería. Para luego hacer una reflexión crítica sobre el papel del Estado multicultural en Colombia.

\section{Avances doctrinales}

Es importante resaltar, el amplio trabajo que ha desarrollado la Corte Constitucional para lograr el reconocimiento de las comunidades étnicas como "sujetos" de derechos fundamentales. Estas habían sido, por mucho tiempo, invisibilizadas en el país y sometidas a las leyes de las mayorías.

De igual manera, es importante aclarar que estas conclusiones van dirigidas al trabajo doctrinal del reconocimiento al derecho a la consulta previa, realizado hasta el momento por la Corte Constitucional. Debido al corto alcance de este trabajo, no se puede evaluar que tan eficaces han sido las sentencias de la Corte Constitucional. Puesto que los casos analizados, estrictamente de minería, inician en el 2009. Por esto, son procesos que todavía están en desarrollo y no hay certeza del cumplimiento de los fallos en los que la Corte Constitucional, ha reconocido el derecho a la consulta previa y ha sancionado a quienes han hecho caso omiso de este.

Podemos decir que, no existe un esfuerzo real del legislador para crear normas que regulen efectivamente el derecho de consulta previa. Aunque existen decretos administrativos que intentan establecer límites a este derecho. En consecuencia, es la Corte Constitucional por medio de la jurisprudencia que ha establecido la forma adecuada de llevar a cabo este procedimiento.

Acerca de las sentencias, podemos decir que en ellas se muestra que la Corte Constitucional privilegia el derecho a la consulta previa sobre el derecho del Estado a la extraccion de recusos naturales. Aún así, el concepto y las reglas fijadas sobre la consulta previa no son homogéneas. Partimos de sentencias abiertas, donde se fijan meros 
principios como: la buena fe y el mutuo respeto, la transparencia, el diálogo intercultural, la participación libre y responsable, la publicidad, la información previa, la celeridad y la representación legítima. Para luego dar un alcance mucho más amplio, afirmando que las decisiones de las comunidades pueden llegar a considerarse vinculantes. Lamentablemente, la última sentencia revisada afirma que la consulta previa no es un derecho a al veto, lo que contradice la jurisprudencia anterior

\section{Multiculturalismo y políticas de desarrollo}

A partir de los años setenta, hay una reformulación de las luchas sociales, los movimientos giran a pensar las diferencias culturales, más allá de la clase social. Estas ideas son apropiadas por instancias internacionales y transnacionales, que luchan por atender los reclamos identitarios. A partir de estas luchas de los setentas y ochentas, en los años noventa se da el "giro multicultural". Donde muchas naciones en el mundo adoptan políticas de inclusión a grupos minoritarios. Al mismo tiempo, hay un fuerte movimiento económico que desindustrializa el norte y reindustrializa el sur, con condiciones laborales ínfimas. Produciendo una nueva clase obrera: mujeres y trabajadores con marcas étnicas (Zambrano, 2012). Es así, como se da un doble movimiento. Por un lado se establecen derechos especiales para grupos minoritarios, y por el otro, la economía mundial se reestructura creando nuevas clases obreras y reduciendo el tamaño de los Estados.

El multiculturalismo es entonces, un discurso que permitió a unos grupos minoritarios de la población colombiana alcanzar derechos diferenciales de gran peso, tal como el derecho a la consulta previa. Que no es un derecho de veto declarado, pero permite la lucha y protección de terrenos ancestrales ante la amenaza de la explotación de recursos naturales. Al mismo tiempo, el multiculturalismo ha invisibilizando las luchas de otros grupos no étnicos.

Los pobladores rurales, por ejemplo, son un sector vulnerable de la sociedad civil colombiana, como víctimas del conflicto armado, desplazados o como una población históricamente marginada. Ellos no poseen las mismas ventajas que las poblaciones étnicamente reconocidas, ni de los mecanismos efectivos para la protección de derechos colectivos. Aunque sufren de igual o peor manera las políticas de desarrollo del país. Por eso, podemos concluir que, aunque la Corte Constitucional ha avanzado a pasos 
agigantados en la protección de derechos étnicos, esto no implica que hallan verdaderos cambios estructurales que garticen la equidad entre los colombianos.

\section{Bibliografía}

ANAYA, James (2010). "Informe del Relator Especial sobre la situación de los derechos humanos y libertades fundamentales de los pueblos indígenas". Nueva York: Asamblea General de la Organización de la Naciones Unidas - ONU. Consultado desde http://www2.ohchr.org/english/bodies/hrcouncil/docs/15session/A.HRC.15.37_sp.pdf

BONILLA, Daniel. (2006). La constitución multicultural. Bogotá: Pontificia Universidad Javeriana.

BOTERO, Catalina. (2003). "Multiculturalismo y derechos de los pueblos indígenas en la jurisprudencia de la Corte Constitucional”. En: Precedente, 45-87. Cali: Facultad de Derecho y Ciencias sociales, Universidad Icesi

CAVIEDES, Mauricio (2002). Antropología y movimiento indígena. Bogotá: Universidad Nacional. www.humanas.unal.edu.co/colantropos

LOPÉZ, Diego E. (2006). El derecho de los jueces. Bogotá: Editorial Legis. 139-192

SALINAS, Carlos E. (2011). "La consulta previa como requisito obligatorio dentro de trámites administrativos cuyo contenido pueda afectar en forma directa a comunidades indígenas y tribales”. En: Colombia. Revista Derecho del Estado, no. 27, pp. 235-259.

ZAMBRANO Marta. (2012). Multiculturalismo y patrimonialización. Conferencia 29 de Marzo Cali: Universidad Icesi.

\section{Sentencias}

Sentencia T-380/ 1993 (Sentencia hito), Magistrado Ponente (MP): Eduardo Cifuentes Muñoz

Sentencia SU-039/ 1997, Magistrado Ponente: Antonio Barrera Carbonell

Sentencia T-880 / 2006, Magistrado Ponente: Alvaro Tafur Galvis.

Sentencia T-769/2009, Magistrado Ponente: Nilson Pinilla Pinilla

Sentencia T-1045A/2010, Magistrado Ponente: Nilson Pinilla Pinilla

Sentencia T-129/2011 Jorge Iván Palacio Palacio 


\section{Anexo}

Balance jurisprudencial sobre si se vulnera el derecho fundamental de las comunidades étnicas a la consulta previa cuando se realizan obras, proyectos y/o actividades mineras o petroleras que tengas la potencialidad de afectar sus territorios con fundamento en la potestad que tiene el Estado colombianos para explotar los recursos naturales en el subsuelo del territorio nacional.

\begin{tabular}{|c|c|c|}
\hline $\begin{array}{l}\text { Derecho } \\
\text { fundamental de } \\
\text { las comunidades } \\
\text { étnicas a las } \\
\text { consulta previa }\end{array}$ & $\begin{array}{l}\text { * T-380/1993 } \\
\text { MP. Eduardo Cifuentes Muños } \\
\text { * SU-039/1997 } \\
\text { MP. Antonio B. Carbonell } \\
\text { * T-880/2006 } \\
\text { MP. Álvaro Tafur Galvis } \\
\text { * T-769/2009 } \\
\text { MP. Nilson Pinilla Pinilla } \\
\text { * T-1045A/2010 } \\
\text { MP. Nilson Pinilla Pinilla } \\
\text { * T-129/2011 } \\
\text { Jorge I. Palacio Palacio }\end{array}$ & $\begin{array}{l}\text { Potestad que } \\
\text { tiene el Estado } \\
\text { colombiano para } \\
\text { explorar los } \\
\text { recursos naturales } \\
\text { en el subsuelo del } \\
\text { territorio nacional }\end{array}$ \\
\hline
\end{tabular}

